\title{
FOUCAULT DE NORTE AO SUL. ENTREVISTA COM CAROLINA DE SOUZA NOTO E ERNANI PINHEIRO CHAVES
}

\section{APRESENTAÇÃO:}

A revista PRACS recebeu, durante o ano de 2018, uma série de trabalhos acadêmicos para compor o seu Dossiê Biopoder: reflexões interdisciplinares sobre o controle. Para completar o material deste dossiê, convidamos uma pesquisadora e um pesquisador brasileiros, especialistas em Foucault e lecionando em pontos distintos do país, para responderem algumas questões relacionadas aos temas que permearam os artigos recebidos. A Dra. Caroline de Souza Noto ${ }^{3}$, professora do Departamento de Filosofia da Universidade Federal de Santa Catarina e o Dr. Ernani Pinheiro Chaves ${ }^{4}$ é professor titular da Faculdade de Filosofia da Universidade Federal do Pará. Ambos receberam cinco questões por e-mail formuladas por Débora Aymoré e Ilze Zirbel, antecedidas por um pequeno texto de introdução ao tema geral do dossiê. Dispuseram-se, então, a refletir sobre elas e respondê-las. Em seguida, as suas respostas foram organizadas de maneira conjunta pelas entrevistadoras para essa publicação.

${ }^{1}$ Bacharel em Direito (UFPA, 2004), Especialista em Filosofia e Epistemologia das Ciências Humanas (UFPA, 2007), Mestre em Filosofia (USP, 2010), Doutora em Filosofia (USP, 2015) com estágio de pesquisa no exterior com bolsa CAPES (University of Miami, FL, 2013-2014), Pós-doutorado (USP, 2017 - 2018). De 2017 a 2019, Professora substituta do Colegiado de Filosofia da Universidade do Estado do Amapá (UEAP), atualmente, Professora substituta do Departamento de Filosofia da Universidade Federal do Paraná (UFPR).

${ }^{2}$ Graduada em História pela Fundação Universidade Regional de Blumenau (FURB) e em Teologia pela Escola Superior de Teologia da IECLB (EST), Mestre em Sociologia Política pela Universidade Federal de Santa Catarina (UFSC) e Doutora em Filosofia pela Universidade Federal de Santa Catarina (UFSC).

${ }^{3}$ Graduada em filosofia pela Universidade de São Paulo. Fez mestrado, doutorado e pós-doutorado na mesma instituição. Atualmente é membro do GT Filosofia Francesa Contemporânea da ANPOF. Atua na área de História da Filosofia Contemporânea, com ênfase em questões ligadas à ontologia, antropologia filosófica e epistemologia das ciências humanas.

${ }^{4}$ Graduado em Administração pela Universidade Federal do Pará (1978), Mestre em Filosofia pela Pontifícia Universidade Católica de São Paulo (1986) e Doutor em Filosofia pela Universidade de São Paulo (1993). É Professor Titular da Faculdade de Filosofia e foi Coordenador do Programa de Pós-Graduação em Filosofia da Universidade Federal do Pará de 2011 a 2014. É também Professor Permanente no Programa de Pós-Graduação em Psicologia da UFPA e no Programa de Pós-Graduação em Psicologia da UFS (Universidade Federal de Sergipe). Durante o Doutorado realizou estudos e pesquisas na Faculdade de Teologia Evangélica (1989-1991) e na Universidade Técnica (1992), ambas em Berlim, Alemanha. Realizou estágio de Pós-Doutorado em 1998, também na Universidade Técnica de Berlim e em 2003 na Bauhaus-Universität, de Weimar, na Alemanha. Em janeiro e fevereiro de 2013 foi Pesquisador Visitante na Universidade Técnica de Berlim. Tem experiência na área de Filosofia, com ênfase em Filosofia Alemã, em especial Nietzsche e a Escola de Frankfurt, no pensamento de Michel Foucault e no âmbito da Filosofia da Psicanálise. É Membro da Nietzsche-Gesellschaft (Naumburg/Alemanha) desde 1990, do GT Nietzsche da ANPOF e é um dos Editores da revista Estudos Nietzsche. Foi Membro do Comitê Assessor de Filosofia/Teologia do CNPQ entre julho de 2011 e junho de 2014, tendo sido o Coordenador do referido Comitê no período de novembro de 2013 a junho de 2014. De março a junho de 2015, realizou Estágio Sênior de Pesquisa, com Bolsa do CNPQ, na École Normale Superieure de Paris (França), sob a supervisão do Dr. Paolo DIorio. 


\section{A ENTREVISTA:}

Formulado pelo filósofo francês Michel Foucault (1926 - 1984), o biopoder recebe deste autor tratamento duplo: por um lado, epistemológico e histórico e, por outro, político e social. O que nos permite afirmar que a abordagem de Foucault é interdisciplinar, na medida em que epistemologia, história, política e sociologia formam áreas relativamente distintas, cujos limites porosos permitem que se interpenetrem a depender da temática tratada, levando ao questionamento da divisão estanque do conhecimento em áreas muitas vezes incomunicáveis. Foucault, desse modo, enfatiza a complexidade e a abrangência na abordagem das relações sociais de poder que, quando dirigidas aos corpos e às mentes, originam o surgimento do biopoder, desde sua forma pré-moderna (poder soberano) e suas duas formas modernas (poder disciplinar e biopolítica).

A complexidade das sociedades contemporâneas, no entanto, desafia as humanidades, na medida em que o pressuposto de Foucault é a da relação entre saber e poder. Considerando a interação entre a ciência e os valores, o controle exercido sobre a natureza desde a idealização e materialização do projeto baconiano impacta, no limite, no controle humano e social, incentivando modos de produção e de autocompreensão humana, que estabelecem o ser humano como dominador da natureza e das demais espécies. Porém, a distribuição desigual dos bens e serviços são indícios de que o discurso de dominação da natureza extrapola para o exercício do controle do humano sobre o próprio humano.

Questão 1: Se considerarmos o marco da publicação de "A ordem do discurso", em 1970, como o início do projeto que desenvolve a analítica do poder projetada no discurso e que, posteriormente, ganha dimensões de caráter produtivo, e considerando os quase cinquenta anos desde àquela publicaşão, pergunta-se: é preciso atualizar o pensamento de Foucault, on sua analitica ainda circunscreve de modo satisfatório o poder? Como defini-lo?

Carolina Noto: Por se tratar de uma filosofia crítica que se ocupa sobretudo em fazer um diagnóstico do presente, a analítica do poder deve ser, sim, sempre atual. E pelo que posso perceber, tem bastante gente tentando fazer isso. Recentemente, por exemplo, dei um minicurso de extensão na UFSC sobre biopoder. Apareceram vários alunos; a maioria vindo de fora da Filosofia e utilizavam Foucault como instrumento metodológico para pensar diferentes tipos de práticas e de mecanismos de poder, na segurança pública, na saúde, na educação, no direito, no urbanismo etc. Tenho a impressão que é principalmente fora da Filosofia onde mais se atualizam ou se aplicam as análises foucaultianas do poder. Isso não significa, contudo, que o diagnóstico que Foucault fizera esteja ultrapassado. Muito pelo contrário. O interesse em torno do tema do biopoder é sinal disso. Muita coisa que Foucault falou no contexto do biopoder e da biopolítica reverbera hoje e tem despertado interesse: a maneira como ele entende o neoliberalismo; a aparente contradição entre um poder que promove a vida, mas que ao mesmo tempo deixa matar ou morrer; a ingerência da economia na ética, da lógica econômica no âmbito da relação do indivíduo consigo mesmo, com a ideia de sujeitos empreendedores de si mesmo e de capital humano. Enfim, uma série de temas que me parecem super atuais.

Ernani Chaves: O próprio Foucault, em diversos e numerosos momentos de sua obra, a revê, a atualiza ao seu modo, deixando de lado algumas coisas, retomando outras, mas, 
principalmente, realizando deslocamentos, os quais acompanham os deslocamentos dos seus objetos de pesquisa. Com a questão do "poder" não foi diferente. Da concepção de "repressão", tão presente na "História da Loucura" até a concepção produtiva do poder e de sua noção de "microfísica do poder", um longo caminho foi percorrido. Mesmo em cursos no Collège de France, como "Teorias e instituições penais" e "A sociedade punitiva", a noção de repressão ainda se fazia presente. É apenas a partir do curso “O poder psiquiátrico”, de 19731974, que uma nova concepção de poder começa a se impor, efetivamente, culminando com as grandiosas análises do "poder disciplinar" em "Vigiar e punir" (1975) e que se ampliam e se desdobram na concepção de "biopolítica/biopoder", no primeiro volume da "História da sexualidade” (1976). E quando pensávamos que essa longa caminhada estivesse completa, novos deslocamentos são operados, quando Foucault intensifica sua discussão sobre o neoliberalismo, com o aparecimento da noção de "governamentalidade", a qual redimensiona o lugar do Estado e, ao mesmo tempo, da noção de "poder pastoral". E a história não acabou uma vez que os livros publicados dentro do projeto da "História da Sexualidade" e os cursos sobre a antiguidade greco-romana, novamente nos colocam diante da relação entre o poder e o dizer verdadeiro (a parrêsia) ou ainda entre o poder e as formas de subjetivação. Diante disso, só posso dizer que não existe uma única e definitiva concepção de poder em Foucault, que ele próprio compreendeu, por exemplo, que apenas a concepção de “disciplina” não poderia explicar a dinâmica das nossas sociedades ou ainda que era preciso encontrar também formas efetivas de resistência, que ele chamou de "contra condutas". Assim sendo, embora seja muitas vezes difícil e complicado para nossas cabeças acostumadas a compreender a filosofia a partir da ideia de sistema, é preciso aprender a conviver com um pensamento, que se apresenta sempre na forma do "ensaio", da "tentativa", que está sempre aberto a reformulações.

Questão 2: E quanto ao Biopoder? Vivemos ainda em uma estrutura social que comporta a experiência iniciada no século XVIII, em que o Estado representa um papel estratégico na gestão da vida da sociedade, operando sobre os individuos e as populações, visando à saúde e à produção?

Carolina Noto: Tenho a impressão que hoje em dia a gente tem que relativizar um pouco o papel do Estado, sobretudo no Brasil. Quando Foucault fala do biopoder, ele se refere a um período que coincide com o nascimento do liberalismo econômico e com uma concepção de Estado que deve se ocupar com as questões sociais, isto é, com aquilo que garante uma vida, não necessariamente boa, mas produtiva; um Estado que se ocupe com a educação, com a saúde, com a segurança e com a mobilidade urbana, por exemplo. É nesse contexto que Foucault faz todas suas análises sobre as reformas que acontecem desde o final do século XVIII até o início do XX: reformas penais, reformas educacionais, reformas na saúde, reformas urbanas. Desse ponto de vista, as análises do biopoder têm a ver com a noção de Estado de bem-estar social, na medida em que o Estado, com suas políticas públicas, é figura central no que diz respeito à gestão da vida da população: é ele quem promove as campanhas de vacinação, as diretrizes do ensino, as reformas nas cidades, as políticas de segurança etc. Quando Foucault passa a analisar o biopoder do ponto de vista do neoliberalismo, parece haver uma mudança no lugar e no papel do Estado; não que ele saia de cena, mas a função de regular o social, ou de gerir a vida da população, usando os termos de Foucault, parece ficar mais descentralizada, visto que a iniciativa privada passa também a se ocupar disso. Não é, portanto, que o Estado não tenha mais papel estratégico no interior do biopoder, mas divide com as 
instâncias privadas da sociedade a gestão da vida. E é aqui, me parece, que o econômico toma por completo o campo da política e, por conseguinte, o da ética, visto que a política, em regime de biopolítica, interfere diretamente no domínio mais íntimo dos homens, aquele da relação do indivíduo consigo mesmo.

Diria mesmo que o que vemos hoje é uma promiscuidade entre a instância pública e privada no que diz respeito à gestão da vida, de tal modo que muitas vezes é difícil identificar se a implementação de uma prática faz parte de uma tática pública, estatal, ou de uma tática privada. Uma política de segurança pública, por exemplo, que incentiva o armamento da população, é uma tática estatal para preservar a vida da população (mesmo que essa tática implique num aumento de mortes; essa é, pois, a contradição intrínseca do biopoder: é um tipo de poder que promove a vida, fazendo e deixando morrer!), ou uma tática de interesses privados da indústria armamentista? Provavelmente as duas coisas.

Ernani Chaves: Como disse na resposta a primeira pergunta, a questão do biopoder redimensiona em vários aspectos a questão do Estado, embora Foucault continue afastado das concepções clássicas acerca da origem e da função do Estado moderno, sejam aquelas advindas da tradição que vai de Hobbes a Rousseau, seja aquela que engloba Marx, os marxismos e o freudo-marxista. Foucault quer entender como determinadas práticas constituem um determinado Estado, práticas que ele chama de "governamento". Com isso, nas suas análises do neoliberalismo ele mostra, com muita clareza, em que medida a exigência do "Estado mínimo", por um lado, comporta, por outro, a exigência da presença do Estado em efetivas formas de controle, o que chamamos, em geral, de "políticas públicas". Apenas um exemplo: há uma espécie de consenso ou de uma aceitação como verdade, de que o aleitamento materno é a melhor forma de alimentação do bebê. Com isso, evita-se o aumento da mortalidade infantil e o perigo de doenças sérias, algumas degenerativas. Uma política pública, que possa minorar essa situação é sempre bem-vinda. Cria-se então um programa nacional de aleitamento materno, destina-se a esse programa um aporte financeiro significativa e o aloja numa unidade básica de saúde. Então, começam as questões: a quem esse programa se dirige diretamente: À mãe da classe média ou à burguesa ou às mulheres pobres, da periferia, cuja única possibilidade de amparo relativo à saúde é o "posto" do seu bairro, da sua comunidade? O dispositivo biopolítico opera de forma sutil, nesses casos, sempre falando em nome da saúde, sempre legitimado pela ciência, mas cuja outra face é o controle e as formas de normalização do corpo feminino, no caso da mulher pobre. Mais ainda: uma vez inscrita no programa, essa mulher terá muita dificuldade de sair dele, não poderá reclamar e dizer, por exemplo, que a amamentação deixa seus mamilos doendo e que ela não quer ficar com os seios feios, tem medo de deixar de ser desejada pelo marido ou companheiro. A ela é interditada toda uma série de desejos, os quais, para as mulheres da classe média ou da burguesia, são inteiramente permitidos e tolerados.

Questão 3: A partir da leitura das obras de Foucault, percebemos o esforço empreendido por este autor que, por um lado, exprime a influência do poder sobre os corpos e as mentes e, por outro lado, procura situar este corpo segundo alguns marcadores, quando trata das prisões, dos hospitais, das escolas etc., como lugares direcionados para certos tipos corpos, a partir dos quais se aplica e se produz saber. É possivel interpretar que este autor utilizava em sua analitica do poder marcadores hoje centrais para pesquisas interseccionais, tais como gênero, classe e raça? 
Carolina Noto: Não me parece que as noções de gênero, classe (no sentido de classe social) e raça sejam centrais no pensamento de Foucault. Apesar disso, acho que é possível, sim, encontrarmos essas questões no interior de sua reflexão. No interior das análises das instituições feitas por Foucault (e vou ficar com aquelas duas que mais lhe interessam: o hospital psiquiátrico e a prisão), as noções que poderiam ser consideradas como "marcadores" de suas pesquisas, são aquelas de doença mental e de delinquência. E é importante notar que essas noções, mais do que referentes a questões de identidade sexual, estrato social ou grupo biológico, dizem respeito a um critério clínico de normalidade. É o critério do normal e do patológico que interessa Foucault desvendar, problematizar e compreender. Podemos mesmo dizer que toda pesquisa foucaultiana em torno do nascimento das ciências humanas, em particular da psicologia, tem como objetivo compreender o aparecimento de certa concepção de homem que o classifica, em diversos domínios (o da sexualidade, o do aprendizado, o da sociabilidade, da afetividade, o do pensamento, o da linguagem etc.) ou como normal ou como patológico. Nesse sentido, toda a filosofia de Foucault consiste na compreensão dos aparatos teóricos e práticos (o que ele chama de dispositivo) que possibilitaram tal definição e tal classificação. Poderíamos, porém, nos perguntar se não seria possível encontrar, além dos critérios modernos de normalidade, outros critérios de classificação e de valoração dos homens, tais como os critérios de gênero, de classe social, de raça. Como se os padrões modernos de normalidade fossem contemporâneos, e inseparáveis, da maneira como, na modernidade, se pensa a diferença entre homens e mulheres, entre pobres e ricos e entre um povo e outro. Foucault não se ateve a essas diferenciações, mas seguramente deixou em aberto o espaço para que elas fossem pensadas.

Ernani Chaves: Depende de quem lê e como se lê. Mas, principalmente, é preciso afastar a ideia de que Foucault é uma espécie de "salvador da pátria" e que suas teorias vão resolver uma série de problemas, senão todos. Grande parte da recepção brasileira, em especial na Educação e na Psicologia Social, caem nessa armadilha. É claro que Foucault é fundamental para a grande modificação sofrida pelo feminismo e suas teorias, a partir dos meados da década de 1970, de tal modo que essas teorias se tornaram impensáveis sem ele. É claro que, sem seu pensamento, a Teoria Queer talvez não tivesse nascido. É claro que suas críticas aos modelos educativos e à posição da escola como "disciplinadora" insuflou vida nova no campo da Educação. É claro que ele ajuda os psicólogos a ficarem mais críticos, em primeiro lugar em relação a eles próprios. Mas, isso não significa que ele pode ser tomado como aquele que vai resolver todos os problemas. Eu diria, para ser mais objetivo: que Foucault tem uma contribuição indispensável às questões de gênero e raça, mesmo que, ao contrário da questão do racismo, ele não tenha nunca se utilizado da noção de "gênero", o que lhe rende críticas até hoje. Por outro lado, mais difícil e mais complexo é entender a questão da "classe", pois isso significaria entender bem esse outro campo complexo e cheio de obstáculos, que é o das suas relações com Marx e com os marxismos. O investigador prudente e precavido, deve se movimentar com cautela nesse emaranhado, mas também deve tentar se abster das conclusões precipitadas, sejam elas favoráveis ou não. Não esqueçamos que tanto a fascinação quanto a recusa prévia não são bons caminhos para se entender o pensamento de um filósofo.

Questão 4: Além do lugar especificamente traçado para certos corpos, o que os situa segundo um conjunto de saberes, podemos verificar certas técnicas de poder agindo não apenas no passado, no estabelecimento de certas rotinas compreendidas como técnicas de direcionamento das forças vitais dos corpos, mas também projetando-se 
para o futuro. Para além da cura de doenças, o desenvolvimento no campo das ciências da vida e da saúde possibilita a manipulação dos fenômenos biológicos com o intuito de aperfeiçoar certas características bumanas, sejam elas físicas ou cognitivas. Como posicionar-se diante dessa possibilidade de "melhoramento bumano"?

Carolina Noto: Quando vocês falam em “técnicas de poder projetando-se para o futuro", imagino que têm em mente a discussão de Foucault sobre eugenia. A questão é levantada de maneira rápida no final do curso de 1976, "Em defesa da sociedade", e no primeiro volume da "História da sexualidade, A vontade de saber", do mesmo ano. O interessante da análise de Foucault, me parece, é que o problema acerca do "melhoramento humano" aparece tanto como um problema ético e político, quanto como epistemológico e metafísico. Quando se fala em "melhoramento humano", tem-se em mente certo modelo ideal de homem que se quer atingir e, por conseguinte, certo modelo ou certo "tipo" de homem que não se quer ser. Um primeiro modelo a ser seguido, um segundo modelo a ser evitado e excluído. Para Foucault esse é o primeiro problema suscitado por um pensamento eugenista e diz respeito ao estatuto ontológico do homem e da possibilidade de conhecer o que é o homem. A eugenia, contudo, traz consigo um grande risco ou perigo ético e político: afinal, quem decide o que o homem deve ser, o que é normal e o que é patológico, o que é bom e o que é ruim? Quem, afinal, decide quem deve viver e quem deve morrer? Essa decisão será sempre uma decisão que implica relações de poder, feita sempre de um ponto de vista interessado e, por isso mesmo, seguindo Foucault, permeada por estratégias de dominação. O risco ético e político do "melhoramento humano", portanto, é o de cair numa política de exclusão, extermínio e eliminação daqueles que ameaçam a vida e a saúde de uma suposta "humanidade" em vias de realização, de uma suposta raça superior ou de uma suposta classe de homens melhores e mais desenvolvidos. Nessa direção, portanto, quando se fala em "melhoramento humano", a grande questão é pensar que tipo de exclusão e dominação ela implica: às custas de quem e a favor de quem é o "melhoramento"?

Ernani Chaves: Foucault, como Nietzsche, não acredita nas promessas dos "melhoradores" da humanidade, título, aliás, de uma das seções de "Crepúsculo dos Ídolos". Isso não significa desconhecer ou mesmo recusar os avanços da ciência e sua contribuição, mas significa sempre dispor-se a questionar se os avanços tecnológicos e científicos não respondem a certas questões, tão antigas quanto a filosofia grega, acerca da "natureza humana". Uma coisa é entender bem o que significam as pesquisas no campo das "neurociências", por exemplo. Ninguém pode desconhecer a importância de estudos e pesquisas sobre o cérebro, que podem favorecer o combate a doenças graves. Outra coisa é querer reduzir a vida emocional, psíquica, aos ditames das "neurociências", como se elas operassem numa zona neutral, objetiva, indiferentes a questões de ordem ética e política.

Questão 5: Finalmente, qual o cenário e os direcionamentos atuais das pesquisas sobre Biopoder no Brasil ou na sua instituição?

Carolina Noto: Percebo que há atualmente no Brasil grande interesse pelo tema do biopoder e diria que as pesquisas se dividem basicamente em dois tipos. Há pesquisas de cunho mais teórico; são em geral pesquisas de história da filosofia, feitas nos departamentos de filosofia e se dedicam tanto à compreensão aos textos de Foucault sobre o assunto, como a autores mais contemporâneos, como Agamben ou Espósito, por exemplo, que apresentam novas 
interpretações sobre o biopoder e a biopolítica. Mas há também as pesquisas mais práticas, que se valem metodologicamente das análises de Foucault para compreender práticas de biopoder que não foram tematizadas pelo filósofo. São pesquisas, diria, que usam Foucault, ou, como apresentado na primeira questão, que atualizam suas análises. Na UFSC, chamaria a atenção para o trabalho da Sandra Caponi, do Departamento de Sociologia, que desenvolve uma espécie de arqueologia e genealogia da medicina e da psiquiatria no Brasil. Acredito que as duas perspectivas são importantes e interessantes. Fazer história da filosofia é essencial, pois o pensamento de um filósofo nunca está completamente assimilado; é sempre preciso voltar a ele, compreender suas perguntas e deixar que ele suscite novos questionamentos, ou como diz Foucault, deixar que ele nos ajude a pensar diferente. Por outro lado, é também central à mobilidade do pensamento, pôr em uso a filosofia, fazer dela um uso prático; usar, por exemplo, a pesquisa arqueológica e genealógica em diferentes domínios a fim de compreender criticamente nossa sociedade, nossa cultura, nossos hábitos e nossos valores.

Ernani Chaves: As questões estão avançando. Os estudos foucaultianos no Brasil ainda são muito direcionados pelos estudos e pesquisa realizados na França. Novamente, sem desconhecer essa importância, é muito bom, necessário e importante, que a discussão internacional sobre Foucault ultrapassa, e muito, a recepção francesa. No momento, tenho encaminhado minhas pesquisas a partir da entrada em cena, nessa discussão, do pensamento de Nietzsche. Nesse caso, meus interlocutores são Roberto Esposito e Vanessa Lemm, principalmente. Mas, por outro lado, a questão do biopoder hoje é muito ampliada, mesmo no Brasil, para o entendimento de fenômenos que não foram estudados por Foucault. O que é mais que desejável, é necessário. Os outros campos de conhecimento, com suas perspectivas próprias, podem fazer uma apropriação interessante do tema do biopoder. Há também, hoje, um interesse por autores como Membeb e sua concepção de "necropolítica". Enfim, não podemos mais deixar de reconhecer, que a noção de biopoder se tornou um operador fundamental no campo da Filosofia Política.

\section{NOSSOS AGRADECIMENTOS:}

Primeiramente, nós, Débora Aymoré e Ilze Zirbel, gostaríamos de agradecer aos professores Carolina Noto e Ernani Chaves pela generosa disponibilidade em participarem desta entrevista.

Em segundo lugar, ao Colegiado de Filosofia da Universidade do Estado do Amapá (UEAP), que nos proporcionou momentos de aprendizado coletivo na IV Semana Amapaense de Filosofia, realizada de 26 a 29 de novembro de 2018 no Campus 2 da UEAP, imprescindível para a maturação das ideias sobre o "biopoder" que dialogam diretamente com esta entrevista.

E, em terceiro lugar, ao Programa de Pós-graduação em Filosofia da Universidade de São Paulo (USP) e ao Programa de Pós-graduação em Filosofia da Universidade Federal de Santa Catarina (UFSC), sendo esta entrevista um dos resultados dos estágios pós-doutorais realizadas, respectivamente, por Débora Aymoré e Ilze Zirbel. 